\title{
Job Satisfaction among Support Staff in Twelve Ohio Academic Libraries
}

\section{Coleen Parmer and Dennis East}

\begin{abstract}
This article uses Paul E. Spector's Job Satisfaction Survey to study 434 responses to a 1989 survey of support staff in twelve state-supported academic libraries in Ohio. Satisfaction was reported in five job dimensions (supervision, coworkers, work, benefits, and pay), but workers were dissatisfied in four job dimensions (operational procedures, communication, contingent rewards, and promotion). Dissatisfaction was widespread among technical workers and generally increased with experience for all workers. Surprisingly, satisfaction was high among part-time workers and, except regarding promotion, higher for women than men.
\end{abstract}

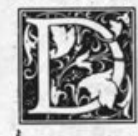

efining job satisfaction accurately and adequately is no easy task. A review of the literature reveals a variety of terms used to describe the phenomenon. However, most analysts agree that job satisfaction is related to the individual's feelings or emotions toward work rather than to intellectual or rational reactions. Paul E. Spector defines job satisfaction as "an emotional-affective response to a job or specific aspects of a job: it is assumed to represent a cluster of evaluative feelings about a job."1

Subodh Gopal Nandy suggests,

The experience of satisfaction or dissatisfaction with individual's work is the consequence of the extent of his positive or negative job attitudes. Job satisfaction is not a permanent attitude nor is it a momentary attitude. It is only a relatively enduring state which undergoes a change with the needs of the individual, the capacity of work situation which fulfills these needs, and the individual's own perception of the situation. ${ }^{2}$
Nandy's point bears repetition: the individual's perception of the work situation and whether or not needs are being met causes either satisfaction or dissatisfaction. Two workers in the same setting can have quite different emotional reactions to the work.

\section{LITERATURE REVIEW}

Theories of job satisfaction and methods for measuring it abound. Three schools of thought important to the study of job satisfaction have been identified. The physicaleconomic school emphasizes the role of the physical arrangement of work, physical working conditions, and pay. Contending that man is a rational being, F. W. Taylor reasoned in 1912 that a worker receiving the highest possible earnings with the least amount of fatigue would be satisfied and productive. Proponents of this view studied the effects of hours of work and rest on fatigue and performance, and environmental factors such as illumination, ventilation and noise, boredom, and monotony. ${ }^{3}$

The Hawthorn Studies, conducted in 1920 by Elton Mayo and his colleagues, 
emphasized the role of good supervision, cohesive work groups, and friendly employee-management relations in job satisfaction. The social, or human relations, school hypothesized that social relationships were more important to job satisfaction than were economic incentives. The influence of this view extended well into the $1950 \mathrm{~s}^{4}$

Robert Hoppock's first intensive study of job satisfaction, performed in 1935, concluded that a multiplicity of factors affected job satisfaction. In his view, achievement affected worker attitudes as much as fatigue, monotony, working conditions, and supervision..$^{5}$ Not until the late 1950s, when the work itself or growth school was expounded by Fredrich Herzberg, Bernard Mausner, and Barbara Block Snyderman, did Hoppock's views become accepted. Although proponents of the older schools of thought abound, the growth of skills, efficacy, and responsibility while performing mentally challenging work are recognized as vital to job satisfaction. ${ }^{6}$

Several researchers utilizing a variety of methods have studied job satisfaction in a library setting. Those studies that have either included library support staff, wholly or in part, or contained conclusions particularly relevant for the authors' study deserve special attention.

Annette L. Hoage identified low salary and the lack of opportunity for advancement as causes of employee turnover among professionals and nonprofessionals in two university libraries. She concluded that, although salary and chances for advancement were instrumental, they were not the only reasons employees resigned. ' Lawrence D. Prybil's survey of librarians, clerical workers, and service employees in one university library employed two questionnaires: one to determine the level of job satisfaction and another for direct supervisors to measure job performance. He concluded that a low but positive relationship existed between job satisfaction and performance, but that a direct correlation between occupational level and job satisfaction did not exist. $^{8}$
William J. Vaughn and J. D. Dunn administered the Job Description Index (JDI) to employees in six university libraries to measure five dimensions of satisfaction: pay, the work, promotional opportunities, coworkers, and supervision. Neither a library nor any department in one of the libraries scored consistently high or low on all aspects of satisfaction. The research emphasized the role and impact of management upon worker satisfaction and productivity and suggested that managers use the findings to determine strengths and weaknesses within their organizations. ${ }^{9}$

Using the Minnesota Satisfaction Questionnaire (MSQ), Asadollah Azad measured job satisfaction among paraprofessionals. He found public service employees more satisfied than those in technical service areas. In a refutation of the Herzberg Motivational-Hygiene or Two-Factor theory, Azad concluded that motivational and hygienic factors were not totally independent of each other as originally posited. ${ }^{10}$ Steven Seokho Chwe's study of satisfaction among reference librarians and catalogers generally supports Azad's findings. Although Chwe found no significant difference in the level of overall job satisfaction between the two groups, he concluded catalogers were significantly less satisfied than reference librarians in several dimensions of their jobs: creativity, social service, and variety. ${ }^{11}$ George P. D'Elia concluded that job environment, rather than gender, type of library, or vocational needs, affected job satisfaction. He identified supervisory climate and intrinsic characteristics of the job itself as the most important determinants of satisfaction. ${ }^{12}$

In 1983, Beverly P. Lynch and Jo Ann Verdin, surveying 384 library employees in three large academic libraries, adopted a satisfaction scale developed by Jerald Hage and Michael Aiken. They found:

1. Older workers were more satisfied than younger workers.

2. Experienced employees were more satisfied than those with less experience.

3. Those who planned to be working in the same library five years hence 
were significantly more satisfied than persons with other plans.

4. Those lacking supervisory responsibility had the lowest satisfaction while department heads were the most satisfied.

5. Reference department employees had significantly higher levels of satisfaction than employees of any other department, except acquisitions.

6. Professional librarians were more satisfied than nonprofessional staff.

In their study, gender did not significantly influence job satisfaction. ${ }^{13}$ Lynch and Verdin replicated the study in 1987 and reached a similar conclusion: significant variations in job satisfaction occur among departments and among occupational groups in libraries. ${ }^{14}$ llene F. Rockman concluded, after surveying 220 uni- versity faculty and librarians, that gender alone could not be viewed as a predictor of job satisfaction. Rather, such variables as autonomy and decision making correlated highly with satisfaction. ${ }^{15}$

An analysis of job satisfaction within an institution should serve as an indicator of morale as well as of a successful operation.

In the most recent studies, Donna $\mathrm{K}$. Fitch surveyed support staff in sixteen Alabama academic libraries, using the JDI to test satisfaction and its relationship to seventeen variables. She found that the size of the institution, gender, and years of worker experience had significant impact on worker satisfaction on one or more JDI scales. ${ }^{16}$ Patricia A. Kreitz and Annegret Ogden compared job responsibilities and satisfaction of librarians and support staff in California university libraries. This study, the largest one of its kind conducted so far, included 563 support staff and 338 librarians. Finding a surprising amount of overlap in job responsibilities, the study concludes that librarians are more satisfied than support staff, especially in the areas of promotion, job development, and influence. ${ }^{17}$

\section{THE CURRENT STUDY}

The notion of a happy worker as a productive worker has been increasingly questioned in recent literature examining job satisfaction. It seems obvious, however, that successful management of any type of organization depends largely upon high morale and satisfaction among the personnel. An analysis of job satisfaction within an institution should serve as an indicator of morale as well as of a successful operation. Support staff in academic libraries comprise the majority of all employees, making them an important indicator of the working climate. Support staff reactions to organizational structure, job classifications, personnel policies, working conditions, and other institutional characteristics can provide strong feedback for library administrators. Accordingly, this study focused on support staff.

Several terms have been used to identify library employees who do not hold a professional position: paraprofessionals, nonprofessionals, subprofessionals, library clerks, technical assistants, and library associates. The term support staff has been chosen for this study because it is the most generic and refers to most personnel in a library except professional librarians, custodial workers, and student assistants. It is also the term preferred by the Academic Library Association of Ohio (ALAO) Support Staff Interest Group, an Ohio library group made up primarily of support staff working in academic libraries in Ohio. In the spring of 1989 , library administrators in thirteen state-supported academic institutions in Ohio were sent a request to participate in this support staff survey and to provide a list of job titles, the number of support staff employed, and the name of a contact willing to distribute the surveys and letters. Administrators at twelve of the libraries agreed to distribute the survey to all employees, except professional librarians, custodial workers, and student assistants. A total of 719 surveys were mailed and 434 usable surveys were returned for a response rate of 60.4 percent. 


\section{SELECTING A SURVEY INSTRUMENT}

Three survey instruments, the MSQ, the JDI, and the Job Satisfaction Survey (JSS) were considered for this study. The MSQ was rejected because of its length and its gender bias. The JDI, developed primarily to measure satisfaction in an industrial setting, was eventually rejected in favor of the JSS developed in 1985 by Paul E. Spector for specific use in human service, public, or nonprofit sector organizations. Spector administered his questionnaire to over $3,000 \mathrm{em}$ ployees. A multitrait, multimethod comparison of the JSS and the JDI provided evidence for discriminant and convergent validity, and further tests determined the relationship of the JSS to other variables, such as employee characteristics, leadership, and organizational commitment. Spector concluded that the overall results were evidence of the JSS's reliability and construct validity. ${ }^{18}$

\section{DESCRIPTION OF THE JSS}

The JSS is composed of thirty-six items, each an evaluative statement about the job. Agreement with a statement indicates either a positive or a negative attitude about the job because half the items are worded positively (i.e., "I feel I am being paid a fair amount for the work I do"), and half are worded negatively ("Raises are too few and far between").

The thirty-six items test attitudes toward nine different aspects of work. These aspects, which Spector calls job dimensions, cover:

- Benefits: including pension, medical coverage, annual leave, and paid vacations.

- Communication: the imparting or interchange of thoughts, opinions, or information by speech or writing.

- Contingent rewards: appreciation and recognition, including praise for accomplishment, credit for work well done, and criticism.

- Coworkers: including their competence, helpfulness, and friendliness.

- Operational procedures: including the organization's rules, procedures, and red tape.
- Pay: including amount, fairness or equity, and method of payment.

- Promotions: including opportunities for, fairness of, and basis for.

- Supervision: including supervisory style and influence, technical and human relations, and administrative skills.

- Work: including intrinsic interest, variety, opportunity for learning, difficulty, amount, chances for success, and control over pace and methods. ${ }^{19}$

These nine job dimensions are broken down into nine subscales. Each subscale is composed of four items, two worded positively, two negatively. An example from the "coworkers" subscale should clarify this approach.

Item 7: I like the people I work with.

Item 16: I find I have to work harder at my job than I should because of the incompetence of people I work with.

Item 25: I enjoy my coworkers.

Item 34: There is too much bickering and fighting at work.

Items 7 and 25 are positively worded, while items 16 and 34 are negatively worded. Degrees of agreement or disagreement with these four items explore attitudes toward coworkers.

Each item is measured on a Likert rating scale with six agree-disagree response choices: (1) disagree very much, (2) disagree moderately, (3) disagree slightly, (4) agree slightly, (5) agree moderately, and (6) agree very much. The value of each item ranges from 1 to 6 points. A score of 6 on positively worded items indicates high satisfaction. Negatively worded item responses are inverted so that 1 equals 6,2 equals 5 , and so on. Consequently, strong disagreement on negatively worded items is scored as a 6 and reflects high satisfaction after score inversion. The subscale score consists of a total of the four items' scores for a range of 4 (low satisfaction) to 24 (high satisfaction).

In the example of the coworkers subscale, a respondent circling 6 on items 7 and 25 would score 12 points (6 points per item), and circling 1 on items 16 and 34 would again score 12 points (6 points per item) because of the score inversion of the negatively worded statements. The respon- 
dent would receive a total of 24 points ( 4 items times 6 points) - very high satisfaction-for the subscale called coworkers.

The JSS provides a quantified assessment of nine identified job dimensions, thus permitting the investigation of those aspects of a job a worker finds either satisfying or dissatisfying. The JSS also provides an overall satisfaction score which is a sum of all thirty-six item scores ranging from a low of 36 (low satisfaction) to a high of 216 (high satisfaction).

Some respondents refused to complete all thirty-six items, contending that the subscale questions appeared too similar. In the current study, forty-seven respondents (10.8 percent) failed to answer at least one item. Several respondents said they had answered the question already. Spector reported that 8.8 percent of his test respondents failed to answer one or more questions. ${ }^{20}$ To overcome this weakness of the JSS, a single missing item within a subscale was replaced by the mean of responses to the remaining three items.

Having selected the JSS to rate satisfaction, the researchers developed an additional questionnaire to gather information about survey respondents. The personal profile sought specific information about position and personal background, while directly investigating specific research objectives to determine whether worker characteristics such as gender, job classification, and years of experience could be used to predict satisfaction. A third part of the survey asked open-ended questions about the respondents' attitudes toward their jobs.

\section{ANALYSIS OF THE DATA}

Table 1 shows job satisfaction for all support staff. The total number of respondents (n) of 422 was derived as the lowest number of responses to any single item. Job dimensions are in rank order from highest satisfaction mean to lowest. These means are compared to Spector's returns. The job dimension subscales range from a low of 4 to a high of 24. Mean scores that fall above the midpoint of 14.5 indicate a degree of satisfaction while mean scores falling below the midpoint indicate a degree of dissatisfaction.

Five of the nine job dimensions fell above the 14.5 mid-point. Support staff find supervision, with a mean of 18.41 ,

TABLE 1

JOB SATISFACTION FOR ALL SUPPORT STAFF

MEANS, STANDARD DEVIATIONS, AND STANDARD ERROR OF MEASUREMENT FOR RANKED JOB DIMENSIONS

\begin{tabular}{lcccc}
\hline Job Dimensions & $\mathrm{N}$ & Mean & SD & Spector's Means \\
\hline Supervision & 422 & 18.41 & 5.57 & 19.9 \\
Coworkers & 422 & 17.44 & 4.02 & 18.8 \\
Work itself & 422 & 16.58 & 4.27 & 19.2 \\
Benefits & 422 & 16.29 & 4.40 & 13.1 \\
Pay & 422 & 14.93 & 4.26 & 10.5 \\
Operational procedures & 422 & 14.19 & 4.47 & 12.5 \\
Communication & 422 & 14.07 & 4.77 & 14.0 \\
Contingent rewards & 422 & 13.90 & 5.35 & 13.4 \\
Promotion & 422 & 10.15 & 4.85 & 11.5 \\
Ovierall & 422 & 135.96 & 29.22 & 133.1 \\
& Range & Dissatisfaction & Midpoint. & Satisfied \\
\hline Subscales: & $4-24$ & $4-14.4$ & 14.5 & $14.6-24$ \\
Overall: & $36-216$ & $36-126.4$ & 126.5 & $126.6-216$ \\
\hline
\end{tabular}


the major source of job satisfaction. Coworkers and work itself also ranked high as satisfying job aspects, with means of 17.44 and 16.58 , respectively. These same three dimensions also rated as the top three among Spector's respondents. The findings support, in part, D'Elia's conclusions that supervisory climate and intrinsic characteristics of the work itself are the most important determinants of satisfaction..$^{21}$ Benefits and pay were also satisfying dimensions for Ohio library support staff but not for Spector's population.

Operational procedures (rules, procedures, red tape) and communication fell slightly below the midpoint, indicating these dimensions were slightly dissatisfying, while staff dissatisfaction was even greater for contingent rewards (recognition and appreciation).

Hoage discovered as early as 1950 that lack of opportunity for advancement played an important role in employee turnover. ${ }^{22}$ Kreitz and Ogden's recent study also provides strong evidence that lack of promotion contributes to dissatisfaction, particularly among support staff..$^{23}$ In the current study, promotion (that is, the opportunity for promotion) clearly causes the greatest dissatisfaction, with a mean of 10.15 . In view of the large number of respondents who identified themselves as having been promoted, this result needs further examination. Question 12 (part A of the survey) asks staff, "Have you been promoted during your employment in this library? (including through job reclassification or job transfer)." A total of $253(58.3 \%)$ responded affirmatively. Yet, contrary to expectations, those who had been promoted were less satisfied than those unpromoted respondents in eight of the nine job dimensions. Only in the pay subscale did promoted workers score higher. The satisfaction means of unpromoted workers, although not statistically significant except on the coworkers subscale, were higher than those promoted. These unusual results may revolve around respondents' perceptions of promotion and may indicate promoted staff's greater recognition of a career barrier. Ultimately, the lack of the M.L.S. degree looms as an impassable barrier to promotion to professional ranks. Job reclassification often injects the employee into an adversarial role with library administration, while job transfer may mean a move away from familiar coworkers, supervisors, and job tasks.

Dissatisfaction with contingent rewards further contributes to the contention that support staff resent the M.L.S. degree barrier. Despite years of service and high levels of education and training, support staff perceive a lack of status, recognition, and appreciation for their work. Administrators should acknowledge that promotion and contingent rewards are the greatest sources of job dissatisfaction among support staff. On the other hand, the overall satisfaction mean (135.96) is well over the midpoint (126.5) and somewhat higher than Spector's results. This, and the fact that five of the nine dimensions are satisfying, should be encouraging news.

Table 1 reveals general trends of satisfaction and dissatisfaction among all respondents, while table 2 examines various worker groups and satisfaction means. Other studies of library staff found that satisfaction is influenced by worker characteristics, such as gender, area of work or department, and years of experience. The current study examines eleven variables: gender, full- or parttime work, educational background, job classification, library size, years of work, area of work, work with patrons, supervisory responsibilities, promotion, and future commitment to the organization. The surveys were coded and run on the Statistical Package for the Social Sciences (SPSS). The eleven variables were run against each of the nine subscales and against overall satisfaction. Table 2 shows the eleven variables ranked by the number of subscales and overall satisfaction scale with statistically significant differences in satisfaction means.

The last five variables (commitment, educational background, library size, promotion, and supervising) generated two or fewer significant scales. Analysis of the results would be entirely too impressionistic. Consequently, this study 
TABLE 2

DEMOGRAPHIC VARIABLES

RANKED BY NUMBER OF SIGNIFICANT SCALES

\begin{tabular}{lcc}
\hline & Subscales & $\begin{array}{c}\text { Overall } \\
\text { scale }\end{array}$ \\
\hline Area of work & 5 & Yes \\
Years of work & 4 & Yes \\
Work with patrons & 4 & Yes \\
Job classification & 3 & Yes \\
Full/part-time & 3 & Yes \\
Gender & 3 & No \\
Commitment & 1 & Yes \\
Educational background & 1 & No \\
Library size & 1 & No \\
Promotion & 1 & No \\
Supervising & 0 & No \\
\hline
\end{tabular}

focuses on the first six variables that generated enough significant scales to suggest patterns.

Respondents were asked to identify their area of work as public service, technical service, both, or other. Those who selected both are presumed to work in a branch or department library that does both public service and technical processing, while those who selected other are presumed to work in offices. Table 3 shows job satisfaction means by area of work. Five subscales and overall satisfaction were statistically significant.

The data indicate a strong connection between satisfaction and where one works. Clearly, those who work in public areas express more satisfaction than those in technical services. In scale A (overall satisfaction), B (contingent rewards), C (coworkers), and F (work itself), public service staff exhibited more satisfaction than those in technical service departments. Staff in department or branch libraries ranked second in satisfaction and office workers ranked third. Scale B also illustrates that department library staff showed significantly more satisfaction than technical staff. These results support Azad's findings that public service employees are more satisfied than their colleagues in technical service. ${ }^{24} \mathrm{~A}$ lead- ing factor in such satisfaction may be interaction with users. This interaction provides immediate feedback to library staff on the importance of their work.

Human service workers may view the chance to help people as gratifying and as contributing to self-esteem. It is no statistical accident that scale B, called contingent rewards (recognition and appreciation), confirms that public service and department library staff are significantly more satisfied than technical service staff. Additional support may be found in Chwe's finding that "catalogers are significantly less satisfied than reference librarians about the social service aspect of their job-the chance to do things for other people." 25

Scale D (communication) also reveals public service workers as significantly more satisfied than technical service workers. Office workers ranked second in satisfaction over the third-ranked department workers. The scores indicate that those in public service and in offices may have more access to official lines of communication.

Only on scale E (operational procedures) did technical service workers not rank last in satisfaction. Public service employees again ranked highest in satisfaction, statistically higher than the last-ranked department library employees. Operational conditions, such as red tape, procedures, and rules, may be viewed as negative factors in the department libraries.

Table 4 displays job satisfaction by years of work experience. Respondents were asked, "How many years have you worked in this library?" Respondents were grouped into four categories: group A ( 0 to 5 years of experience), group B (6 to 10 years), group C (11 to 15 years), and group D (16 or more years). Previous studies show mixed results. Lynch and Verdin showed the most experienced workers to be the most satisfied. ${ }^{26}$ Fitch found that experience was generally not significant, but that on the scale category called opportunities for promotion, firstyear workers were the most satisfied and workers with the most experience were the least satisfied. ${ }^{27}$ 
TABLE 3

JOB SATISFACTION BY AREA OF WORK SUBSCALES AND OVERALL SATISFACTION

A. Overall satisfaction scale

B. Subscale: contingent rewards

C. Subscale: co-workers

D. Subscale: communication

E. Subscale: operational procedures

F. Subscale: work itself
Area of Work

Public service

Department/branch

Office

Technical service

F ratio 4.53

Public service

Department/branch

Office

Technical service

F ratio 5.48

Public service

Department/branch

Office

Technical service

F ratio 3.99

Public service

Office

Department/branch

Technical service

F ratio 5.13

Public service

Office

Technical service

Departmemnt/Branch

F ratio 2.83

Department/branch

Public service

Office

Technical service

F ratio 3.49 (n)

137

114

24

154

137

114

24

154

137

114

24

154

137

24

114

154

137

24

154

114

114

137

24

154
Mean

$141.25^{*}$

137.87

135.94

$129.16^{*}$

$\mathrm{p}<.01$

$14.76^{\circ}$

$14.58^{*}$

13.46

$12.49^{*}$

$\mathrm{p}<.01$

$18.24^{\circ}$

17.64

17.15

$16.66^{*}$

p $<.01$

$15.19^{*}$

14.58

13.87

$13.06^{*}$

$\mathrm{p}<.01$

$14.91^{*}$

14.67

14.05

$13.33^{*}$

$\mathrm{p}<.05$

$17.10^{*}$

$16.94^{\circ}$

16.75

$15.60^{\circ}$

$\mathrm{p}<.05$

* Significant pairs 


\section{TABLE 4}

JOB SATISFACTION BY YEARS OF EXPERIENCE:

SUBSCALES AND OVERALL SATISFACTION

\begin{tabular}{|c|c|c|c|}
\hline & Years of Experience & (n) & Mean \\
\hline \multirow[t]{5}{*}{ A. Overall satisfaction scale } & A $(0-5)$ & 196 & $140.04^{\circ}$ \\
\hline & D $(16+)$ & 68 & 134.90 \\
\hline & B $(6-10)$ & 98 & 132.79 \\
\hline & $C(11-15)$ & 49 & $126.88^{*}$ \\
\hline & F ratio 3.36 & & $\mathrm{p}<.05$ \\
\hline \multirow{5}{*}{ B. Subscale: contingent rewards } & A $(0-5)$ & 196 & $14.73^{*}$ \\
\hline & D (16+) & 68 & 13.41 \\
\hline & $C(11-15)$ & 49 & 13.03 \\
\hline & B $(6-10)$ & 98 & $12.96^{*}$ \\
\hline & F ratio 3.27 & & $\mathrm{p}<.05$ \\
\hline \multirow[t]{5}{*}{ C. Subscale: benefits } & A $(0-5)$ & 196 & $16.72^{*}$ \\
\hline & D (16+) & 68 & 16.44 \\
\hline & B $(6-10)$ & 98 & 16.05 \\
\hline & $C(11-15)$ & 49 & $14.67^{*}$ \\
\hline & F ratio 2.95 & & $\mathrm{p}<.05$ \\
\hline \multirow[t]{5}{*}{ D. Subscale: operational procedures } & A $(0-5)$ & 196 & $14.81^{*}$ \\
\hline & D (16+) & 68 & 14.07 \\
\hline & B $(6-10)$ & 98 & 14.01 \\
\hline & C (11-15) & 49 & $12.48^{*}$ \\
\hline & F ratio 3.72 & & $\mathrm{p}<.01$ \\
\hline \multirow[t]{5}{*}{ E. Subscale: promotion } & A $(0-5)$ & 196 & $11.13^{*}$ \\
\hline & B $(6-10)$ & 98 & $9.44^{*}$ \\
\hline & C (11-15) & 49 & $9.10^{\circ}$ \\
\hline & $\mathrm{D}(16+)$ & 68 & $8.95^{\circ}$ \\
\hline & F ratio 5.66 & & $p<.01$ \\
\hline
\end{tabular}

* Significant pairs.

The results in table 4 defy simple explanation. The workers with the fewest number of years (group A) manifested the most satisfaction on all scales that produced significant results. Group B ranked third on three scales, lowest on the subscale contingent rewards, and second on the promotions subscale. Group C showed the least satisfaction on all scales except the subscales contingent rewards and promotion, on which they ranked third. Employees in group D ranked second in satisfaction on all scales except the promotion subscale, on which they ranked lowest. Removing group D from consideration, a pattern of progression emerges in which the more years of service a worker has, the greater the decline in satisfaction. Support for this conjecture can be seen in the promotion subscale in which group A ranked first, $B$ second, C third, and D last. These findings match Fitch's. What may be operating with group D is that those who have remained on the job over fifteen years either may have accepted the perceived 
TABLE 5

JOB SATISFACTION BY WORKING WITH PATRONS: SUBSCALES AND OVERALL SATISFACTION

\begin{tabular}{llcc}
\hline & Work with Patrons & (n) & Mean \\
\hline A. Overall satisfaction scale & A Yes & 293 & $137.88^{*}$ \\
& B No & 139 & $130.63^{*}$ \\
& F ratio 5.86 & & $\mathrm{p}<.05$ \\
B. Subscale: contingent rewards & A Yes & 293 & $14.35^{*}$ \\
& B No & 139 & $12.72^{*}$ \\
& F ratio 8.84 & & $\mathrm{p}<.01$ \\
C. Subscale: communication & A Yes & 293 & $14.31^{*}$ \\
& B No & 139 & $13.31^{*}$ \\
& F ratio 4.18 & & $\mathrm{p}<.05$ \\
D. Subscale: work itself & & 293 & $16.85^{*}$ \\
& A Yes & 139 & $15.74^{*}$ \\
& B No & & $\mathrm{p}<.01$ \\
E. Subscale: promotion & F ratio 6.38 & & $10.62^{*}$ \\
& & 293 & $8.95^{*}$ \\
& A Yes & 139 & $\mathrm{p}<.01$ \\
\hline
\end{tabular}

* Significant pairs.

limitations of the work or may be looking forward to retirement. The only job dimension that continues to cause great dissatisfaction for this group is promotion.

This pattern-the more experience, the greater the dissatisfaction-if true, has serious implications for libraries. Ideally, as workers gain experience, they should enjoy greater satisfaction. That such is not the case implies that support staff jobs are dead-end positions and that advancement becomes progressively less likely as one gains experience and expertise.

Table 5 compares the job satisfaction means of staff who work with patrons and staff who do not. In the overall satisfaction scale and all four significant subscales, support staff who work with patrons exhibited significantly more satisfaction than their colleagues who do not. Previous studies predicted, and the results in table 3 confirm, this outcome.

Table 6 shows the levels of satisfaction associated with job classification or title.
Respondents were grouped into five classifications: office personnel, including secretaries, office managers, typists, word processors, and administrative assistants; library assistants; library technical assistants (LTA); library associates; and other (all whose jobs could not be assigned to the first four categories, such as unit heads, computer systems operators, and audiovisual or media production workers). In general, library assistants and office workers showed the most satisfaction, while LTAs were least satisfied.

This pattern also appears on those scales not showing differences at levels of .05 significance. The researchers received lists of support staff job titles used in the participating libraries. Many titles were similar to titles such as library associate or library media assistant, which were frequently listed. But because more than ninety job titles are used in just twelve libraries, categorizing workers was extremely difficult. Much of the previous literature supports the notion that 
TABLE 6

JOB SATISFACTION BY JOB CLASSIFICATION: SUBSCALES AND OVERALL SATISFACTION

\begin{tabular}{|c|c|c|c|}
\hline & Job Classification & (n) & Mean \\
\hline \multirow[t]{6}{*}{ A. Overall satisfaction scale } & (B) Library. assistants & 82 & $141.92^{*}$ \\
\hline & (A) Office workers & 43 & 141.10 \\
\hline & (D) Library.associates & 101 & 136.25 \\
\hline & (E) Other & 15 & 135.80 \\
\hline & (C) L.T.A.s & 164 & $130.84^{*}$ \\
\hline & F ratio 2.47 & & $\mathrm{p}<.05$ \\
\hline \multirow[t]{6}{*}{ B. Subscale: rewards } & (A) Office workers & 43 & $15.47^{*}$ \\
\hline & (E) Other & 15 & 14.67 \\
\hline & (D) Library. associates & 101 & 14.35 \\
\hline & (B) Library. assistants & 82 & 14.22 \\
\hline & (C) L.T.A.s & 164 & $12.81^{\circ}$ \\
\hline & F ratio 2.94 & & $\mathrm{p}<.05$ \\
\hline \multirow[t]{6}{*}{ C. Subscale: promotion } & (A) Office workers & 43 & $11.78^{*}$ \\
\hline & (B) Library. assistants & 82 & $11.18^{*}$ \\
\hline & (E) Other & 15 & 10.67 \\
\hline & (D) Library. associates & 101 & 9.99 \\
\hline & (C) L.T.A.s & 164 & $9.21^{*}$ \\
\hline & F ratio 3.86 & & $\mathrm{p}<.01$ \\
\hline \multirow[t]{6}{*}{ D. Subscale: communication } & (B) Library. assistants & 82 & $15.70^{\circ}$ \\
\hline & (D) Library. associates & 101 & 14.09 \\
\hline & (A) Office workers & 43 & 13.44 \\
\hline & (C) L.T.A.s & 164 & $13.33^{*}$ \\
\hline & (E) Other & 15 & 13.07 \\
\hline & F ratio 3.85 & & $\mathrm{p}<.01$ \\
\hline
\end{tabular}

* Significant pairs.

job titles play a significant role in satisfaction. It is, however, virtually impossible to explore this area in the current study because of the wide range of job titles used in Ohio. Perhaps the task would be more manageable by using the American Library Association support staff titles in the questionnaire and asking respondents to select the title that most closely matches their job. ${ }^{28}$

Respondents were asked to identify themselves as either full-time or parttime workers. Table 7 shows the results of satisfaction in these two categories. This study, the first to examine this vari- able, produced surprising results. Contrary to expectation, part-time workers scored higher satisfaction means in all significant scales (overall, contingent rewards, pay, and promotion). Note that the mean (12.59) on the promotion scale is still below the midpoint (14.5), indicating dissatisfaction. However, this dimension is significantly less dissatisfying to part-time staff than to full-time staff.

The scale called pay, which shows satisfaction among part-time workers, may indicate why these workers are generally more satisfied than their fulltime counterparts. If people accept part- 
TABLE 7

JOB SATISFACTION BY FULL AND PART-TIME WORK: SUBSCALES AND OVERALL SATISFACTION

\begin{tabular}{llrr}
\hline & Full- or Part-Time & (n) & Mean \\
\hline A. Overall satisfaction scale & A part & 42 & $146.29^{*}$ \\
& B full & 389 & $135.06^{*}$ \\
& F ratio 5.42 & & $\mathrm{p}<.05$ \\
B. Subscale: contingent rewards & A part & 42 & $15.74^{*}$ \\
& B full & 389 & $13.65^{*}$ \\
& F ratio 5.79 & & $\mathrm{p}<.05$ \\
C. Subscale: pay & A part & 42 & $16.79^{*}$ \\
& B full & 389 & $14.69^{*}$ \\
& F ratio 9.03 & & $\mathrm{p}<.01$ \\
D. Subscale: promotion & A part & 42 & $12.59^{*}$ \\
& B full & 389 & $9.82^{*}$ \\
& F ratio 12.69 & & $\mathrm{p}<.01$ \\
\hline
\end{tabular}

* Significant pairs.

time work in a university library intending to rise to full-time status, then pay may not cause dissatisfaction because gratification has been postponed. In those cases where workers wish to remain as permanent part-time employees, pay generally supplements family income and will not, if it meets or exceeds labor market averages, cause pronounced dissatisfaction. Also, the work environment offers chances for interesting activities and social interactions for the part-time employee, making contingent rewards and promotion-the most dissatisfying dimensions identified for full-time workers - of lesser importance to part-time employees.

The last variable, gender, is examined in table 8. D'Elia, Rockman, and Lynch concluded that gender was not significant in job satisfaction. ${ }^{29-31}$ Fitch, on the other hand, found women more satisfied than men on all five scales of the Job Description Index. ${ }^{32}$ In the current study, women scored higher than men in three significant subscales: work itself, coworkers, and pay. In fact, women scored higher satisfaction means than men on all scales, except promotion, although the scores were not significantly different except as noted in table 8 .
The final table, table 9, shows the reliability coefficients of the nine subscales. A coefficient alpha score of .7 indicates high reliability of the scale. That is, the questions that make up the subscales measure what they purport to measure. The subscale, operational procedures, with an alpha of 0.6429 , is the only one that is slightly low. Overall, the subscales are highly reliable.

\section{CONCLUSIONS}

An easy, and essentially accurate, generalization that academic library support staff in Ohio appear to be satisfied with their employment situation emanates from this study. In particular, the workers expressed strong satisfaction with supervision, coworkers, work itself, benefits, and pay while disclosing general dissatisfaction with operational conditions, communication, contingent rewards, and promotion. This study's results clearly demonstrate that the promotion and contingent rewards issues need further clarification and study as well as resolution. The linkage of these issues with the lack of an M.L.S. degree for support staff promises no easy solution. 
TABLE 8

JOB SATISFACTION BY GENDER SUBSCALES AND OVERALL SATISFACTION

\begin{tabular}{llrc}
\hline & Gender & (n) & Mean \\
\hline A. Subscale: work itself & A women & 354 & $16.73^{*}$ \\
& B men & 79 & $15.51^{*}$ \\
& F ratio 5.20 & & $\mathrm{p}<.05$ \\
B. Subscale: coworkers & & 354 & $17.61^{*}$ \\
& A women & 79 & $16.63^{*}$ \\
& B men & & $\mathrm{p}<.05$ \\
C. Subscale: pay & F ratio 3.89 & 354 & $15.18^{*}$ \\
& & 79 & $13.59^{*}$ \\
& A women & & $\mathrm{p}<.01$ \\
\hline
\end{tabular}

* Significant pairs.

TABLE 9

RELIABILITY ANALYSIS OF THE SUBSCALES

\begin{tabular}{lcc}
\hline Subscales & Coefficient Alphas & Questions \\
\hline Pay & 0.6909 & $1,10,19,28$ \\
Promotion & 0.8230 & $2,11,20,33$ \\
Supervision & 0.8888 & $3,12,21,30$ \\
Benefits & 0.7318 & $4,13,22,29$ \\
Contingent rewards & 0.8373 & $5,14,23,32$ \\
Operational procedures & 0.6429 & $6,15,24,31$ \\
Coworkers & 0.7517 & $7,16,25,34$ \\
Work itself & 0.7272 & $8,17,27,35$ \\
Communication & 0.7423 & $9,18,26,36$ \\
\hline
\end{tabular}

Variables, by their very nature, may make generalization difficult. Yet, this study supports some conclusions by other researchers, such as Azad, Lynch, and Chwe, that support staff in public areas manifest more satisfaction than those in technical areas. Where one works in a library definitely relates to satisfaction.

The clear, and somewhat disturbing, finding - that the most experienced workers are the most dissatisfied-again provides evidence of the M.L.S. degree roadblock to promotion. This may increase, more than any other variable, dissatisfaction of the most experienced support staff.

Further, the study indicates that the opportunity to work with patrons certainly influences support staff satisfac- tion. Whether job classification or title influences satisfaction cannot be decided because of the wide range of job titles used in Ohio academic libraries.

The study produced two surprising findings with respect to full- or part-time status and pay. Part-time workers exhibited higher levels of satisfaction than full-time workers on the most significant scales, particularly the issue of pay. That part-time support staff seem more satisfied with pay than their full-time counterparts indicates satisfaction relative to average wages for comparable work and to work and social interactions unique to the workplace. In such a context, contingent rewards and promotion, if full-time work is not the goal of part-time work, offer no reason for dissatisfaction. This 
study also supports Fitch's finding that female support staff exhibit more satisfaction than their male counterparts. With the exception of the promotion issue, women showed greater satisfaction than men on all scales.

The reliability analysis revealed that the subscales of the JSS are acceptably reliable. The instrument which was developed to measure job satisfaction among human service workers lends itself very well to the study of library personnel. The JSS was published with Spector's article and is available for researchers to use without Spector's written permission.

Job satisfaction or dissatisfaction, while neither a permanent nor secondary attitude, reflects an individual's perception of the work situation and the meeting of his or her needs. This study provides evidence that while support staff in academic libraries are generally satisfied, significant issues remain to be resolved.

The variety of instruments used to measure job satisfaction among library staff makes comparisons between studies difficult. The use of the JSS in this study produced a number of statistically significant results and has, the authors believe, opened the door to further study using this instrument. In particular, the issues of promotion and recognition should be closely examined in light of worker experience and job classifications. This study adds to the body of conflicting evidence of whether gender is significant or not and if more study in this area is needed. Possibly, gender is a significant factor among support staff, but not among librarians. While this study supports earlier studies that workers in public service are more satisfied than those in technical service, it does not examine workers by departments. The variety of department names among twelve universities produced too many categories to derive statistically sound results, the same as job classifications did. Creating a demographic survey with selected departments and job classifications listed would probably solve this problem and produce interesting results. Finally, since this study was the first to examine full- and part-time workers, additional testing of those results is needed.

\section{REFERENCES AND NOTES}

1. Paul E. Spector, "Measurement of Human Service Staff Satisfaction: Development of the Job Satisfaction Survey," American Journal of Community Psychology 13(June 1985):695.

2. Subodh Gopal Nandy, "Job Satisfaction of the Library Professional," Herald of Library Science 27(July/Oct. 1988):211.

3. Edwin A. Locke, "The Nature and Causes of Job Satisfaction," in Handbook of Industrial and Organizational Psychology, ed. Marvin D. Dunnette (Skokie, Ill.: Rand McNally, 1976), 1298.

4. Ibid., 1299.

5. Ibid., 1299.

6. Ibid., 1299.

7. Annette L. Hoage, "Resignation in Two University Libraries," College \& Research Libraries 11(Jan. 1950):32.

8. Lawrence D. Prybil, "Job Satisfaction in Relation to Job Performance and Occupational Level," Personnel Journal 52(Feb. 1973):94.

9. William J. Vaughn and J. D. Dunn, "A Study of Job Satisfaction in Six University Libraries," College \& Research Libraries 35(May 1974):168-69, 175.

10. Asadollah Azad, "Job Satisfaction of Paraprofessional Librarians: A Comparative Study of Public and Technical Services Departments in Selected University Libraries" (Ph.D. diss., University of Pittsburgh, 1978), 110, 118.

11. Steven Seokho Chwe, "A ComparativeStudy of Job Satisfaction: Catalogers and Reference Librarians in University Libraries," Journal of Academic Librarianship 4(July 1978):139.

12. George P. D'Elia, "The Determinants of Job Satisfaction among Beginning Librarians," Library Quarterly 49(July 1979):283-302. 
13. Beverly P. Lynch and Jo Ann Verdin, "Job Satisfaction in Libraries: Relationships of the Work Itself, Age, Sex, Occupational Group, Tenure, Supervisory Level, Career Commitment, and Library Department," Library Quarterly 53(Oct. 1983):443.

14. - - - "Job Satisfaction in Libraries: A Replication," Library Quarterly 57(Apr. 1987):199.

15. Ilene F. Rockman, "Job Satisfaction among Faculty and Librarians: A Study of Gender, Autonomy, and Decision Making Opportunities," Journal of Library Administration 5(Fall 1984):51, 55.

16. Donna K. Fitch, "Job Satisfaction among Library Support Staff in Alabama Academic Libraries," College \& Research Libraries 51(July 1990):313-20.

17. Patricia A. Kreitz and Annegret Ogden, "Job Responsibilities and Job Satisfaction at the University of California Libraries," College \& Research Libraries 51(July 1990):297312.

18. Spector, "Measurement of Human Service Staff," 707-9.

19. Locke, "Nature and Causes of Job Satisfaction," 1302, provides definitions of the terms, benefits, coworkers, pay, promotions, supervision, and work itself. Spector, "Measurement of Human Service Staff," 699, provides definitions for the terms contingent rewards and operational conditions. See the Random House Webster's College Dictionary, rev. ed. (1975), s.v. "communication."

20. Spector, "Measurement of Human Service Staff," 696.

21. D'Elia, "Determinants of Job Satisfaction," 300.

22. Hoage, "Resignations in Two University Libraries," 32.

23. Kreitz, "Job Responsibilities," 308.

24. Azad, "Job Satisfaction of Paraprofessional Librarians," 110.

25. Chwe, "A Comparative Study of Job Satisfaction," 143.

26. Lynch, "Job Satisfaction: A Replication," 200.

27. Fitch, "Job Satisfaction among Library Support Staff," 317.

28. Lester E. Asheim, "Education and Manpower for Librarianship," ALA Bulletin 62(Oct. 1968):1097. Asheim recommended three subprofessional levels, which he called library clerk, technical assistant, and library assistant-now called clerk, library technical assistant, and library associate. These titles stand as the nonprofessional position titles endorsed by the American Library Association.

29. D'Elia, "Determinants of Job Satisfaction," 295.

30. Rockman, "Job Satisfaction among Faculty," 51.

31. Lynch, "Job Satisfaction: A Replication," 195.

32. Fitch, "Job Satisfaction among Support Staff," 316.

\section{STATEMENT OF OWNERSHIP, MANAGEMENT AND CIRCULATION}

College \& Research Libraries, Publication No. 00100870, is published bi-monthly by the Association of College and Research Libraries, American Library Association, 50 E. Huron St., Chicago, IL 60611-2795. The editor is Gloriana St. Clair, Pennsylvania State University, University Park, PA 16802. Annual subscription price, \$22.50. Printed in U.S.A. with second-class postage paid at Chicago, Illinois. As a nonprofit organization authorized to mail at special rates (Section 423.12, Domestic Mail), the purposes, function, and nonprofit status of this organization and the exempt status for federal income tax purposes have not changed during the preceding twelve months.

\section{EXTENT AND NATURE OF CIRCULATION}

(Average figures denote the average number of copies printed each issue during the preceding twelve months; actual figures denote actual number of copies of single issue published nearest to filing date: September 1992
issue.) Total number of copies printed: 13,256 ; actual 13,330 . Sales through dealers, carriers, strect vendors and counter sales: none. Mail subscription: average 12,473; actual 12,569. Free distribution: average 112; actual 117. Total distribution: average 12,585; actual 12,686. Office use, leftover, unaccounted, spoiled after printing: average 671; actual 644. Total: average 13,256; actual 13,330.

Statement of Ownership, Management and Circulation (PS Form 3526, Feb. 1989) for 1992 filed with the United States Post Office Postmaster in Chicago, September 30, 1992. 